Universidade Tecnológica Federal do Paraná - UTFPR

Campus Ponta Grossa - Paraná - Brasil

ISSN: $1981-3686 /$ v. 04 , n. 01: p. 109-121, 2010

D.O.I.: $10.3895 / \mathrm{S} 1981-36862010000100012$
Revista Brasileira deTecnologia

Agroindustrial

\title{
IMPORTÂNCIA DO TRATAMENTO TÉRMICO NA CASCA DE MARACUJÁ PARA EXTRAÇÃO DE PECTINA
}

\section{IMPORTANCE OF THERMAL TREATMENT ON THE RIND PASSION FRUIT TO PECTIN EXTRACTION}

\author{
Maria Helene Giovanetti Canteri ${ }^{1,2}$; Agnes de Paula Scheer ${ }^{2}$ Christian Ginies $^{3}$ \\ Catherine Marie-Genevieve Claire Renard ${ }^{3,4}$; Gilvan Wosiacki ${ }^{5}$ \\ ${ }^{1}$ Universidade Tecnológica Federal do Paraná - UTFPR - Ponta Grossa - Brasil canteri@ utfpr.edu.br \\ ${ }^{2}$ Universidade Federal do Paraná -UFPR-Curitiba- Brasil agnesps@ufpr.br \\ ${ }^{3}$ Institute National de la Recherche Agronomique - INRA - França-christian.ginies@avignon.inra.fr \\ ${ }^{4}$ Université d'Avignon et Pays de Vaucluse -UAPV- Avignon- França crenard@ avignon.inra.fr \\ ${ }^{5}$ Universidade Estadual de Ponta Grossa - UEPG - Ponta Grossa- Brasil wosiacki@ uol.com.br
}

\begin{abstract}
Resumo
No Brasil, existe um aumento crescente da industrialização do maracujá para produção de suco, resultando em grandes quantidades de subprodutos. O pericarpo do Passiflora edulis mostra-se adequado como fonte de substâncias pécticas. A pectina, um polissacarídeo, é capaz de formar gel sob condições controladas e pode ser utilizada como espessante e estabilizante em alimentos. A manufatura comercial consiste em uma extração química por hidrólise ácida. Dois processos de extração comparativa foram extração ácida $\left(20 \mathrm{~min} ., 8{ }^{\circ} \mathrm{C}\right.$ and $50 \mathrm{mM}$ de ácido nítrico) de matéria prima branqueada e extração aquosa de matéria-prima fresca. As análises específicas do conteúdo de pectina foram rendimento, viscosidade, grau de esterificação, açúcares neutros, ácido galacturônico e perfil no HPSEC. O propósito deste trabalho foi investigar a composição química e propriedades físicas da pectina extraída pelo processo aquoso a frio comparado ao processo ácido a quente. Os resultados das análises indicaram que o branqueamento apresenta um importante papel positivo na composição e propriedades físicas da pectina extraída.
\end{abstract}

Palavras-chave: branqueamento, farinha de casca de maracujá, pectina.

\section{Introdução}

O significativo aumento nas agroindústrias provoca um acréscimo na produção de resíduos, sendo a indústria de suco de frutas produtora de elevada quantidade desses, com potenciais problemas para disposição final. Estes co-produtos podem ser potencialmente utilizados como constituintes de ração animal (FIGUEROLA et al., 2005).

Provavelmente a mais complexa macromolécula na natureza e um dos principais componentes da parede celular, a pectina refere-se a uma família de oligossacarídeos e polissacarídeos, com características comuns, todavia extremamente diversos em sua estrutura fina. O esqueleto péctico é primariamente um homopolímero de $1 \rightarrow 4$ ácido galacturônico, com grau 
variável de grupos carboxilas metil esterificados (VORAGEN et al., 1995; PEREZ et al., 2003; WILLATS et al., 2006; VORAGEN et al., 2009).

O grau de esterificação (DE) é a razão dos grupamentos esterificados de ácido Dgalacturônico pelo total de grupamentos de ácido galacturônico. Este método abrange outros grupos capazes de promover a esterificação além dos grupos metila, como os grupos acetila (SRIAMORNSAK, 2003). O grau de metilação (DM) é expresso como o percentual do total de resíduos de ácido galacturônico esterificados apenas com grupo metoxila (HUISMANN et al; 2004). Segundo o grau de esterificação, a pectina pode ser classificada como de alta metoxilação (HM ou AM), com DE superior a 50\%; na prática entre 50 e 75\%) ou de baixa metoxilação (LM ou BM), com DE inferior a 50\%; na prática entre 20 e 45\% (SRIAMORNSAK, 2003; WILLATS et al., 2006).

O valor global de esterificação é um importante fator de influência sobre a geleificação, associado com outras variáveis interdependentes, como a massa molar, heterogeneidade, $\mathrm{pH}$, grau de amidação, presença de açúcares e outros solutos (BEMILLER, 1986; WILLATS et al., 2006).

Devido à capacidade de geleificação depender do tamanho molecular e grau de esterificação, pectinas de diferentes fontes não apresentam a mesma habilidade de formação de gel em função das variações nestes parâmetros. Em consequência, a detecção de uma larga quantidade de pectina em uma fruta não é suficiente para qualificá-la como fonte comercial de pectina. Novas fontes potenciais permanecem não usuais em função de certas propriedades estruturais indesejáveis (THAKUR et al., 1997; WILLATS et al., 2006). A casca de maracujá tem sido estudada como matéria-prima alternativa para extração de pectina (D'ADDOSIO et al., 2005, PERES e SCHEMIN, 2005; YAPO e KOFFI, 2006; PINHEIRO et al., 2008; KLIEMANN et al., 2009, YAPO, 2009a , YAPO, 2009b).

No estado fresco, a matéria-prima pode ser propensa ao crescimento de fungos produtores de uma larga quantidade de enzimas pécticas. Quantidades significativas de pectinametilesterase nativa foram detectadas em cascas de frutos cítricos. Essa enzima, em contraste à fúngica, produz blocos de material desesterificado característica indesejável para algumas aplicações específicas. (MAY, 1990; THAKUR, 1997).

A produção industrial de pectina comercial pode ser considerada uma extração química, por hidrólise, com ácido mineral diluído a quente e as condições são variáveis em função da matéria-prima e características desejáveis da pectina extraída (MAY, 1990; SAKAI et al, 1993; THAKUR, 1997). Entretanto, é possível a extração de substâncias pécticas pela simples solubilização em meio aquoso (YAPO e KOFFI, 2006).

A alteração no protocolo usual de extração a frio apenas com água reduziria consideravelmente os custos com energia (tratamento térmico e desidratação da matéria-prima e 
aquecimento para extração) e aquisição do ácido. O propósito deste trabalho foi investigar a composição química e propriedades físicas da pectina extraída pelo processo aquoso a frio frente à obtida pelo processo ácido a quente, método usual de produção industrial, indicando se essa mudança seria vantajosa.

\section{Material e métodos}

A farinha matéria-prima foi produzida a partir do mesocarpo ou albedo do maracujáamarelo, parte branca intermediária. Aproximadamente $20 \mathrm{~kg}$ de frutos tiveram a remoção manual do exocarpo, por meio de facas, sendo cortados para retirada da polpa (direcionada para outros experimentos) e do endocarpo, restando o mesocarpo exposto. Esta fração da casca foi submetida a tratamento térmico para inativação de possíveis enzimas, por imersão em água em ebulição durante três minutos, seguido de resfriamento em banho de gelo.

Esse material foi acondicionado em sacos de tecido sintético e centrifugado para eliminar o excesso de água e desidratado a $60{ }^{\circ} \mathrm{C}$ em estufa de circulação de ar, até massa constante (cerca de dezoito horas), seguido de trituração em moinho de facas. A farinha foi tamisada através de peneiras com orifícios de $250 \mu \mathrm{m}(60 \mathrm{MESH})$. Essa farinha seca foi embalada e armazenada em temperatura ambiente. Foi estabelecida a umidade da farinha seca, por secagem direta das amostras em estufa a $105^{\circ} \mathrm{C}$ até massa constante pelo método 012/IV (IAL, 2008).

A extração e o isolamento das pectinas nessa tese foram conduzidos a partir de estudos prévios, com leves modificações (SCABIO et al., 2007; FERTONANI et al., 2009). A farinha de casca de maracujá foi suspensa em água e foi preparada solução ácida de igual volume, a partir da diluição de ácido nítrico 1M. A suspensão ácida deveria apresentar razão final sólido-líquido 1:50 (w/v). Ambos os frascos foram aquecidos até a temperatura de extração e os conteúdos foram misturados em um sistema de condensação, sendo cronometrado o tempo estabelecido. O processo de extração foi interrompido por imersão do recipiente com a suspensão ácida em banho de água e gelo.

As condições de extração ácida a quente foram as seguintes: 20 minutos a $80{ }^{\circ} \mathrm{C}$ com concentração final de ácido nítrico de $50 \mathrm{mM}$, sendo essa pectina codificada como PAS. Foi conduzida também uma extração sem adição de ácido, a frio, com a pectina codificada como FAG. O albedo de maracujá-fresco cortado em tiras foi adicionado de água destilada, numa razão 1:50, permanecendo sob temperatura de refrigeração durante cerca de 12 horas.

A Figura 1 esquematiza o protocolo geral de extração e isolamento das pectinas utilizado. 
Figura 1 - Diagrama geral de extração ácida e precipitação alcoólica de pectinas a partir de farinhas.

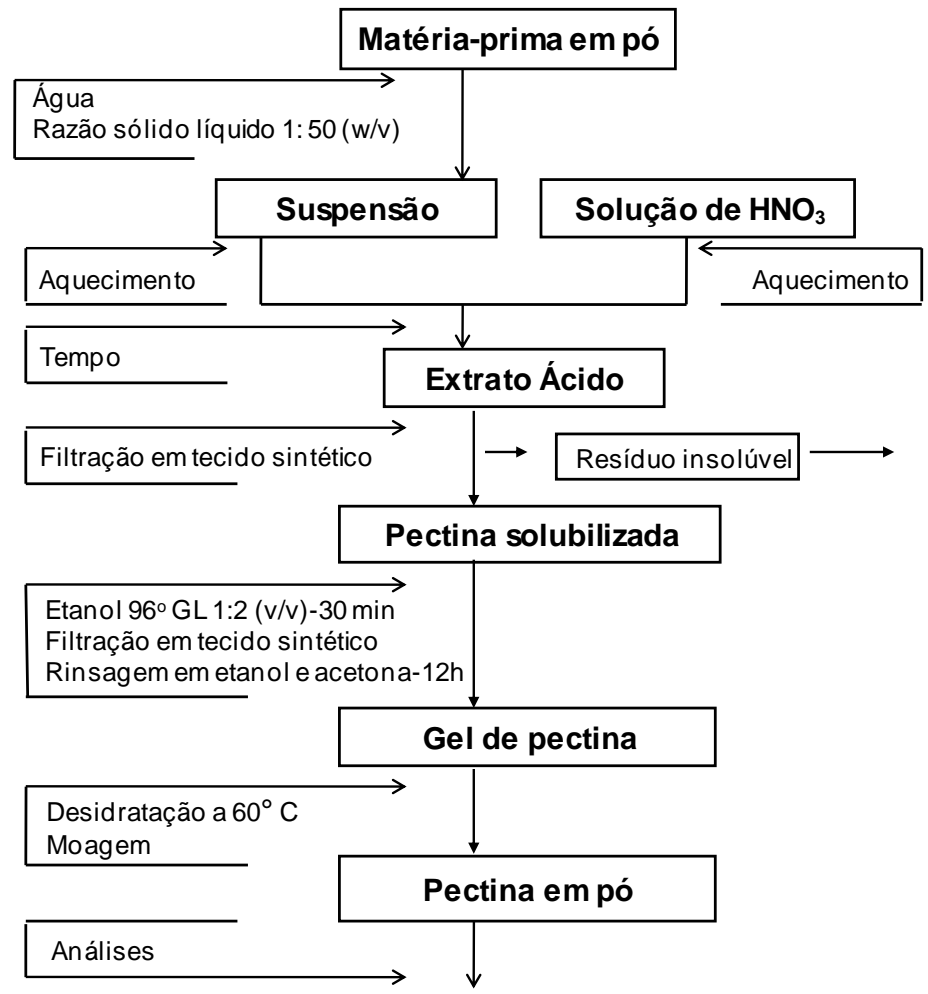

Para o isolamento de pectina solúvel, o resíduo sólido foi separado por filtração em tecido sintético. O extrato ácido líquido foi adicionado a dois volumes de etanol $96^{\circ} \mathrm{GL}$, ambos à cerca de $4{ }^{\circ} \mathrm{C}$ (temperatura média de refrigerador), sob agitação. Nessa fase, a pectina torna-se um gel visível, localizado no fundo (precipitado) ou na superfície (flotado) do líquido etanólico. O sistema permaneceu em repouso por 30 minutos, para a separação do gel de pectina. O gel foi filtrado em tecido sintético e imerso em etanol $96{ }^{\circ} \mathrm{GL}$ durante a noite. Em seguida, foi parcialmente desidratado pela imersão em acetona por poucos minutos, seguida de prensagem em tecido sintético, e conduzido à estufa de circulação a $40^{\circ} \mathrm{C}$ até massa constante (cerca de cinco horas).

A pectina em pó foi acondicionada em recipientes abertos num dessecador com pentóxido de fósforo durante 12 horas aproximadamente e armazenada posteriormente em frascos hermeticamente fechados entre $20-25^{\circ} \mathrm{C}$ (temperatura ambiente do laboratório). As amostras foram homogeneizadas e tamisadas em peneiras com orifícios de $106 \mu \mathrm{m}$ (150 MESH) antes de cada análise.

O rendimento gravimétrico de cada pectina extraída foi calculado a partir da razão entre a massa da pectina desidratada em pó e a massa da farinha desidratada utilizada como matéria-prima, ambas em base seca.

O DE foi determinado por titulação pelo método proposto por Bochek et al.(2001). As condições de extração ácida a quente foram as seguintes: 20 minutos a $80^{\circ} \mathrm{C}$ com concentração final 
de ácido nítrico de 50mM, sendo essa pectina codificada como PAS. Foi conduzida também uma extração sem adição de ácido, a frio, com a pectina codificada como FAG. O albedo de maracujáfresco cortado em tiras foi adicionado de água destilada, numa razão 1:50, permanecendo sob temperatura de refrigeração durante cerca de 12 horas.

O grau de metilação foi estimado pela razão molar entre a concentração de metanol e de ácido galacturônico, expressa pela seguinte equação:

$$
\operatorname{DM}(\%)=\frac{\text { concentração molar de metanol }}{\text { concentração molar ácido galacturônico }}
$$

Para a dosagem do teor de ácido urônico, foi construída uma curva de calibração de cinco pontos com padrão de ácido galacturônico, com concentração variando entre 0 a $100 \mu \mathrm{g} / \mathrm{mL}$ para cada lote de amostras analisadas. Para hidrólise das amostras, cerca de $1 \mathrm{~mL}$ de solução de inositol $(1 \mathrm{mg} / \mathrm{mL})$ foi adicionado sobre 8 a $12 \mathrm{mg}$ de cada amostra (valor exato registrado), em tubos com tampa. Após agitação em vórtex, foram adicionados $1 \mathrm{~mL}$ de ácido sulfúrico $2 \mathrm{M}$, homogeneizados vigorosamente em seguida. Os tubos permaneceram durante três horas a $100{ }^{\circ} \mathrm{C}$, com agitação ocasional, sendo resfriados depois de decorrido esse tempo, sob água corrente. Nos tubos imersos em banho de água e gelo, acrescentou-se $0,5 \mathrm{~mL}$ de amostra hidrolisada, adequadamente diluída, ou da solução padrão, mais $3 \mathrm{~mL}$ de solução de tetraborato em ácido sulfúrico. Os tubos foram agitados com auxílio de vórtex e imersos em banho-maria termostatizado a $80{ }^{\circ} \mathrm{C}$ durante dez minutos. A reação foi paralisada pela imersão dos tubos em banho de gelo e água, até temperatura ambiente. Em cada tubo, foram adicionados $50 \mu \mathrm{L}$ de metahidroxidifenil para as amostras ou $50 \mu \mathrm{L}$ de $\mathrm{NaOH}$ N/8 para os brancos, com agitação intensa em vórtex. A leitura foi feita a $520 \mathrm{~nm}$ em espectrofotômetro Varian Cary 100, depois de exatamente dez minutos de incubação (INRA, 2009a; BLUMENKRANTZ e ASBOE-HANSEN, 1973).

A concentração molar de metanol foi determinada no headspace por cromatografia a gás acoplada à espectroscopia de massa CG (RENARD e GINIES, 2009), depois de saponificação. Amostras de $10 \mathrm{mg}$ de pectina foram dissolvidas em $4 \mathrm{ml}$ de água destilada e saponificadas pela adição de $1 \mathrm{ml}$ de $\mathrm{KOH} 1 \mathrm{M}$ contendo $\mathrm{CD}_{3} \mathrm{OH}\left(7 \mu \mathrm{mol}^{\mathrm{m}} \mathrm{ml}^{-1}\right)$ como padrão interno, em repouso por duas horas em temperatura ambiente. Para cromatografia a gás foi utilizado o equipamento GC-MS QP2010 Shimadzu com coluna capilar Cp-wax-52cb 30 m x 0.32 mm x $0.5 \mu \mathrm{m}$ (Varian, Inc, Palo Alto, USA) equipado com auto-injetor das amostras AOC5000. O frasco selado foi incubado no próprio equipamento a $50^{\circ} \mathrm{C}$ por quinze minutos e então $0,5 \mathrm{ml}$ do headspace foi injetado (razão 1:10). As condições da cromatografia a gás foram: gás carreador hélio a $45 \mathrm{~cm} . \mathrm{s}^{-1} \mathrm{e}$ isotermas de 
temperaturas a $40^{\circ} \mathrm{C}$. As condições do detector de massa foram: modo de ionização eletrônico de impacto $(70 \mathrm{eV})$ e temperatura da fonte de $200{ }^{\circ} \mathrm{C}$ com dados coletados usando SIM para íons selecionados $(\mathrm{m} / \mathrm{z} 31 ; 32 ; 35)$ a 5 scans/s. $\mathrm{O}$ íon em m/z $31\left(\mathrm{CD}_{3} \mathrm{O}^{+}\right)$foi preferido ao em m/z 32 para $\mathrm{CH}_{3} \mathrm{OH}$, em função de resultar num melhor sinal. O íon em m/z 35 é o íon molar para $\mathrm{CD}_{3} \mathrm{OH}$, sendo altamente específico para esse composto. Uma curva de calibração foi elaborada com o metanol na faixa 0.6-6 $\mu \mathrm{mol} \cdot \mathrm{ml}^{-1} \mathrm{com} \mathrm{CD}_{3} \mathrm{OH}$ como padrão interno a $1.4 \mu \mathrm{mol} \cdot \mathrm{ml}^{-1}$. As concentrações de metanol foram calculadas a partir da equação obtida, considerando a área do pico de metanol pela área do pico de metanol deuterado. A massa molar foi calculada considerando o peso molecular da molécula de metanol igual a 32.

A quantificação do metanol na farinha de mesocarpo liofilizado sem qualquer tratamento térmico e na farinha branqueada foi realizada à temperatura de $30{ }^{\circ} \mathrm{C}$. Adicionou-se $3,95 \mathrm{~mL}$ de água a cerca de $200 \mathrm{mg}$ de cada farinha, mais $1 \mathrm{~mL}$ de pectina cítrica $(10 \mathrm{mg} / \mathrm{mL})$ e $50 \mu \mathrm{L}$ de $\mathrm{CD}_{3} \mathrm{OH}$, para um volume total de $5 \mathrm{~mL}$. Foram registrados dez resultados para cada amostra, com intervalo de 21 minutos entre cada leitura. A razão da área do pico de metanol pelo metanol deuterado indica indiretamente o teor liberado em função da desesterificação da pectina adicionada, promovida pela ação enzimática. Essa análise foi qualitativa.

Para caracterização reológica, preparados líquidos pela dissolução de pectina $(1 \mathrm{~g} / \mathrm{L})$ em solvente contendo $\mathrm{NaCl} 90 \mathrm{mM}$, NaF $10 \mathrm{mM}$ e $\mathrm{Na}_{2}$ EDTA $1 \mathrm{mM}$, em pH 6,5, foram filtrados através de membrana de acetato de celulose (Milipore) com poros de 0,45 $\mu \mathrm{m}$, antes de serem pipetadas em um viscosímetro capilar Schoot (capilar nº100, tipo 51310 Cannon-Fenske, Constant $\mathrm{k}=0,015$ ), imerso em termostato transparente CT-52 a $25 \pm 1{ }^{\circ} \mathrm{C}$. O tempo de escoamento foi registrado três vezes com cronômetro para determinar o valor absoluto de viscosidade cinemática. Uma tabela específica para o viscosímetro foi utilizada para corrigir a energia cinética e a viscosidade cinemática foi calculada para cada amostra e solvente, de acordo com as equações:

$$
\begin{aligned}
& \eta_{\text {cin. }}=K(t-v) \\
& \text { I } \eta=\left(\eta_{\text {cin. da solução }}-\eta_{\text {cin. do solvente }}\right) / \eta_{\text {cin. do solvente }} \\
& \eta_{\text {red }}=I \eta / c
\end{aligned}
$$

Onde $\eta_{\text {cin. }}=$ viscosidade cinemática; $K=$ constante para o capilar $n^{\circ} 100 ; t=$ média do tempo de escoamento; $v=$ correção da energia cinética segundo tabela; $\mathrm{I} \eta=$ incremento da viscosidade relativa; $\eta_{\text {red }}=$ viscosidade reduzida; $\mathrm{c}=$ concentração da solução. 
O perfil da massa molar por cromatografia de permeação em gel foi conduzido por cromatografia de exclusão estérica de alta pressão (HPSEC) em um sistema HPLC Varian 9050/9010 equipado com coluna TSK-Gel GMPW (30 cm L x 7,8 mm ID; TosoH Corporation, Japão) em combinação com uma coluna TSK-Gel PXXL $(40 \times 6 \mathrm{~mm})$ a $35^{\circ} \mathrm{C}$ e acoplado a um refratômetro Varian RI-4. O eluente foi tampão acetato de sódio/ ácido acético, pH 3,6, também utilizado como solvente das amostras. Tanto as soluções de pectina (15 g/L, adicionadas de glucose 1,5 g/L) quanto o solvente foram filtrados através de membranas (Phenex RC 0,45 $\mu \mathrm{m}$ ). A eluição foi aproximadamente $0,8 \mathrm{~mL} / \mathrm{min}$ e $20 \mu \mathrm{L}$ de cada amostra foram injetados no sistema. Uma curva de calibração foi construída com padrões de dextrana.

Todos os dados foram apresentados em função do parâmetro de partição $\mathrm{K}_{a v}$, segundo a equação:

$$
\mathrm{K}_{\mathrm{av}}=\left(\mathrm{V}_{\mathrm{e}}-\mathrm{V}_{0}\right) /\left(\mathrm{V}_{t}-\mathrm{V}_{0}\right)
$$

onde:

$\mathrm{V}_{\mathrm{e}}$ = volume de eluição de cada amostra; $\mathrm{V}_{0}=$ volume de exclusão ou volume "morto" da coluna, estabelecido em função do tempo de eluição da dextrana $\mathrm{T} 500$ (Pharmacia LKB Biotechnology) e $\mathrm{V}_{\mathrm{t}}=$ volume total da coluna, obtido a partir do tempo de eluição da glucose (Merck).

A fase apolar obtida por derivatização de alditóis (INRA, 2009b) foi transferida para tubos próprios, para injeção em cromatógrafo gasoso GC-FID HP 5890 Série II (Agilent, Inc, Palo Alto, USA) com coluna capilar de $30 \mathrm{~m}$ x 0,25 mm revestida com película de 0,25 $\mu \mathrm{m}$ DB225 MS (J\&W Scientific, Agilent, Inc, Palo Alto, USA). As condições para análise foram temperatura de injeção de $250{ }^{\circ} \mathrm{C}$ em modo split (razão 1:25), gás carreador hidrogênio a $45 \mathrm{~cm} / \mathrm{s}$ (a $215^{\circ} \mathrm{C}$ ), fluxo da coluna de $1.3 \mathrm{~mL} / \mathrm{min}$ e a temperatura isotérmica a $215^{\circ} \mathrm{C}$.

Cerca de $50 \mathrm{~g}$ das amostras de pectina PAS e FAG, extraídas do albedo de maracujáamarelo, foram encaminhadas por SEDEX ${ }^{\circledR}$ ao laboratório da empresa Herbstreith \& Fox para resultados comparativos e confirmação do grau de esterificação.

\section{Resultados e Discussão}

O rendimento gravimétrico da pectina extraída com ácido nítrico a quente foi aproximadamente $200 \mathrm{~g} \mathrm{~kg}^{-1}$. Estes valores foram mais altos que a soma de pectina aquosa e ácida (142 g. $\mathrm{kg}^{-1}$ ) extraída de pericarpo de maracujá amarelo da Costa do Marfim, usando condições mais severas em extração sequencial (YAPO; KOFI, 2006). KLIEMANN et al.. (2009) registraram rendimentos entre 89-277 g. $\mathrm{kg}^{-1}$ na extração também com ácido nítrico de matéria-prima similar. $\mathrm{O}$ rendimento da extração aquosa a frio foi consideravelmente menos elevado (cerca de quatro vezes 
mais baixo), ainda assim mais elevado que o descrito por YAPO E KOFFI (2006), 29 g.kg ${ }^{-1}$, obtido a partir de matéria-prima preparada como AIS.

A Tabela 1 apresenta os resultados das análises específicas obtidas para a pectina do albedo de maracujá-amarelo.

Tabela 1- Parâmetros qualitativos da pectina extraída do albedo de maracujá-amarelo

\begin{tabular}{|c|c|c|c|c|c|c|}
\hline Amostras & $\begin{array}{c}\text { Rendimento } \\
\text { de pectina } \\
\left(\mathrm{g}^{\left.-\mathrm{kg}^{-1}\right)}\right.\end{array}$ & $\begin{array}{l}\text { DE } \\
(\%)\end{array}$ & $\begin{array}{l}\text { DM } \\
(\%)\end{array}$ & $\begin{array}{c}\eta \operatorname{app~} 1 \% \\
\text { (cP) }\end{array}$ & $\begin{array}{l}\text { Tempo de } \\
\text { eluição } \\
\text { (min.) }\end{array}$ & $\begin{array}{c}\text { Mw } \\
(\mathbf{k D a})\end{array}$ \\
\hline$\overline{\text { PAS }^{*}}$ & 203,4 & 70 & 82 & 120 & 9,3 & 299 \\
\hline $\mathrm{FAG}^{* *}$ & 57,0 & 80 & 97 & 99 & 9,7 & 142 \\
\hline
\end{tabular}

PAS e FAG- farinhas de albedo de maracujá-amarelo *condições de extração : $80^{\circ} \mathrm{C}, 20$ minutos e $50 \mathrm{mM}$ de ácido nítrico; **extração a $4^{\circ} \mathrm{C}$, overnight, sem adição de ácido **** $\eta$ app= viscosidade aparente.

A pectina extraída do mesocarpo apresentou alto grau de esterificação e de metoxilação. Com relação ao grau de esterificação para mesma matéria-prima, esse resultado é similar aos encontrados por D'ADDOSIO et al. (2005), KLIEMANN (2006) E PINHEIRO (2007) e diferente do valor citado por YAPO E KOFFI (2006), que caracterizaram-na como de baixo grau de esterificação. A diferença do grau de metilação reside na forma de calcular o percentual, a partir de valores obtidos por métodos diversos (colorimétrico para o ácido galacturônico e cromatográfico para o metanol).

Para soluções salinas de pectina na concentração de $1 \%$, a maior viscosidade foi observada na pectina obtida por extração ácida a quente. A viscosidade está coerente com a massa molar aproximada obtida por exclusão estérica para as amostras,ou seja, maior viscosidade associada a maior massa molar. A menor viscosidade aparente relativa da amostra FAG pode ser devida a possíveis resquícios de pectina metil esterase na pectina, ativados durante a solubilização das amostras para análise. A extração ácida a quente normalmente desnatura enzimas que ainda possam estar presentes na matéria-prima e que venham a ser precipitados e incorporados à amostra.

A massa molar relativa da pectina extraída foi mais elevada que os valores de $63 \mathrm{kDa}$ para pectina extraída com água sem adição de ácido e 51kDa para pectina extraída com ácido nítrico a quente (YAPO; KOFFI, 2006), bem como 172-176 kDa para pectina extraída com ácido nítrico a quente (YAPO, 2009a). Atividade enzimática pectinolítica foi detectada a partir da liberação crescente de metanol em mesocarpo liofilizado, relacionada à desesterificação promovida por pectinametilesterase endógena, visto que a farinha apresentava baixo teor de umidade, desfavorável ao desenvolvimento de fungos produtores de enzimas exógenas. Isso indica a necessidade de branqueamento da matéria-prima. A amostra liofilizada apresentou liberação crescente de metanol.

$\mathrm{Na}$ Tabela 2 podem ser encontrados os resultados das análises de açúcares das pectinas analisadas. 
Tabela 2- Teor de açúcares das pectinas

\begin{tabular}{ccccccccccc}
\hline Amostra & $\begin{array}{c}\text { Rha } \\
(\mathbf{m g} / \mathbf{g})\end{array}$ & $\begin{array}{c}\text { Fuc } \\
(\mathbf{m g} / \mathbf{g})\end{array}$ & $\begin{array}{c}\text { Ara } \\
(\mathbf{m g} / \mathbf{g})\end{array}$ & $\begin{array}{c}\text { Xyl } \\
(\mathbf{m g} / \mathbf{g})\end{array}$ & $\begin{array}{c}\text { Man } \\
(\mathbf{m g} / \mathbf{g})\end{array}$ & $\begin{array}{c}\text { Gal } \\
(\mathbf{m g} / \mathbf{g})\end{array}$ & $\begin{array}{c}\text { Glc } \\
(\mathbf{m g} / \mathbf{g})\end{array}$ & $\begin{array}{c}\text { GalA/ } \\
\text { Rha** }\end{array}$ & $\begin{array}{c}\text { TAN } \\
(\mathbf{m g} / \mathbf{g})\end{array}$ & $\begin{array}{c}\text { GalA } \\
(\mathbf{m g} / \mathbf{g})\end{array}$ \\
\hline PAS $^{*}$ & 4 & 1 & 7 & 6 & 3 & 11 & 16 & 25 & 47 & 828 \\
FAG** $^{*}$ & 3 & 2 & 8 & 9 & 5 & 11 & 14 & 23 & 52 & 704 \\
\hline
\end{tabular}

*condições de extração : $80^{\circ} \mathrm{C}, 20$ minutos e $50 \mathrm{mM}$ de ácido nítrico; **extração a $4^{\circ} \mathrm{C}, 12$ horas, sem adição de ácido *** razão molar ****não se aplica para este parâmetro; GalA= ácido galacturônico; TAN= total de açúcares neutros; $\mathrm{DP}=$ desvio-padrão das médias com 11 graus de liberdade e $\alpha=0.05$.

O perfil de açúcares da pectina extraída a frio sem adição de ácido e com ácido a quente do maracujá amarelo mostrou-se bastante similar, com predominância da glucose e galactose como açúcares principais. Ambas as pectinas apresentaram mais de 65\% de ácido galacturônico, requerido para que um polissacarídeo extraído seja considerado pectina, de acordo com a legislação dos Estados Unidos e União Européia (WILLATS et al.; 2006). Os dados foram similares aos encontrados por Yapo (2009b) de 63,8\% a 78,3\% em pectina de casca de maracujá, extraída a 80 ${ }^{\circ} \mathrm{C}$, por 90 minutos numa razão sólido/líquido de 1:25. O valor médio da razão molar GalA/Rha foi em média 24, próximo aos valores de 23 e 25 descritos por YAPO (2009a), também em extração com ácido nítrico.

Os resultados das análises realizadas nos laboratórios da empresa Herbstreith \& Fox (H \& F), na Alemanha para a amostra PAS indicaram grau de esterificação de $74 \%$, pouco acima do resultado encontrado neste trabalho. Outros parâmetros determinados foram o conteúdo de ácido galacturônico de $81,4 \%$; o conteúdo de metil-éster de 9,6\%; pH de 2,5 para uma solução de 2,5\%; cinzas de 1,3\%; umidade de 8,3\%; força do gel de 199 USA-SAG e viscosidade de uma solução 2,5\% de 1.111 mPas. A amostra FAG apresentou grau de esterificação de $80 \%$, similar ao encontrado neste trabalho; conteúdo de ácido galacturônico de 78\%; o conteúdo de metil-éster de $10 \%$; pH de 4,96 para uma solução de 2,5\%; cinzas de 6,3\%; umidade de 6,7\%; força do gel de 156 USA-SAG, e viscosidade de uma solução 2,5\% de 576 mPas. Em ambas as amostras de pectina de maracujá, a presença de amido não foi detectada. A capacidade de geleificação e a viscosidade podem ser subestimadas devido à solubilidade pobre e ao enovelamento das amostras. Do ponto de vista analítico, ambas as amostras de pectina de mesocarpo de maracujá foram classificadas como de muito boa qualidade. As pectinas comerciais são padronizadas a $150{ }^{\circ}$ USA-SAG antes da comercialização.

Cerca de 1/3 da pectina extraída do albedo de maracujá-amarelo pode ser extraída a frio, sem adição de ácido (FAG). Se considerada a economia de ácido e energia no processo de extração, bem como os resultados de esterificação e açúcares, similares à pectina extraída com ácido (PAS), poderia ser sugerida alteração econômica no protocolo de produção. Entretanto, a partir dos resultados do tempo de eluição no HPSEC e massa molar aproximada, a cadeia da pectina FAG se mostrou hidrolisada e com baixa viscosidade aparente relativa, reforçando a importância do tratamento térmico da matéria-prima para inativação enzimática. 


\title{
4. Conclusão
}

Embora a composição em açúcares e grau de esterificação tenha sido aproximada, a pectina extraída pelo processo aquoso a frio apresentou rendimento, viscosidade e massa molar menores comparativamente à pectina obtida pelo processo ácido a quente, desfavorecendo sua aplicação na indústria alimentícia.

A matéria-prima sem qualquer tratamento térmico pode favorecer a degradação da pectina, em função de que atividade enzimática pectinolítica foi detectada a partir da liberação crescente de metanol em mesocarpo fresco liofilizado, indicando a necessidade de branqueamento da matériaprima.

\section{Agradecimentos}

Este trabalho teve apoio das seguintes Instituições/Órgãos de Fomento: CAPES, INRA UMR408, GTM-UEPG, UTFPR-Ponta Grossa and UFPR, aos quais os autores agradecem. Especialmente, sinceros agradecimentos a Hans-Ulrich Endre $\beta$ da empresa Herbstreith \& Fox (Alemanha) por amostras de pectina padronizada e por análises realizadas nos laboratórios de sua indústria.

\begin{abstract}
Brazil has an increasing industrialization of passion fruit to juice production and it generates waste. The pericarp of Passiflora edulis was found to give satisfactory results for source of pectic substances. Pectin, a polysaccharide, is able to gel formation under controlled conditions and can be used for thickening and stabilizing foods. Commercial manufacturing consists in a chemical extraction by acid hydrolysis. Two comparative production processes were acid extraction (20 min, $80{ }^{\circ} \mathrm{C}$ and $50 \mathrm{mM}$ nitric acid) of bleaching raw material and aqueous extraction of fresh raw material. The specific analysis of pectin content carried out were yield, viscosity, degree of esterification, neutral sugar, GalA and HPSEC elution profiles. The purpose of this paper was to investigate the chemical composition and physical properties of extracted pectin by cold aqueous process compared with the pectin obtained by hot acid process. The results of analyses showed that the bleaching played an important positive role on the composition and physical properties of pectin extracted.
\end{abstract}

Key-words: bleaching, passion fruit rind flour, pectin.

\section{Referências}

BLUMENKRANTZ N., ASBOE-HANSEN G. New method for quantitative determination of uronic acids. Analytical Biochemistry, v. 54, p. 848-489, 1973.

BOCHEK, A. M.; ZABIVALOVA, N. M.; PETROPAVlOSVSKII, G. A. Determination of the esterification degree of polygalacturonic acid. Russian Journal of Applied Chemistry, v. 74, n. 05, p. 775-777, mai. 2001.

D’ADDOSIO R.D.; PÁEZ G., MARÍN M , MÁRMOL Z., FERRER J. Obtención y caracterización de pectina a partir 
de la cáscara de parchita (Passiflora edulis f. flavicarpa Degener). Revista de la Facultad de Agronomia, Caracas, v. 22, n. 03, jul. 2005. p. 241-251.

FERTONANI H. C. R.; SCABIO A.; CARNEIRO E. B. B.; CANTERI-SCHEMIN M. H.; NOGUEIRA A.; WOSIACKI G. Extraction Model Of Low Methoxyl Pectin from Apple Pomace Effects of acid concentration and time on the process and the product. Brazilian archives of biology and technology. v. 52, n. 1, p 177-185, jan.-fev. 2009.

FIGUEROLA F.; HURTADO M. L.; ESTÉVEZ A. M. CHIFFELE I. ASSENJO F. Fibre concentrates from apple pomace and citrus peel as potential fibre sources for food enrichment. Food Chemistry, n. 91, 395-401, 2005.

HUISMANN M. M. H.; OOSTERVELD A.; SCHOLS H. A. Fast determination of the degree of methyl esterification of pectins by head-space GC. Food Hydrocolloids, v. 18, p. 665-668, 2004.

IAL-Instituto Adolfo Lutz. Métodos físico-químicos para análise de alimentos. ZENEBON O., PASCUET N. S., TIGLEA P. Método 012/IV. 1 ed. digital, p 98-99, 2008.

INRA-INSTITUTE NATIONAL DE LA RECHERCHE AGRONOMIQUE. UMR 408. Dosage des oses neutres par la méthode des acetates d'alditols. Avignon: protocolo de atividade prática fornecido em 07 jan. 2009a.

INRA-INSTITUTE NATIONAL DE LA RECHERCHE AGRONOMIQUE. UMR 408. Dosage acide galacturonique colorimétrie-01. Avignon: protocolo de atividade prática fornecido em 12 fev. 2009b.

KLIEMANN E., SIMAS K. N., AMANTE E. R., PRUDÊNCIO E. S.; TEÓFILO R. F., FERREIRA M. M. C.; AMBONI R. D. M. C. Optimisation of pectin acid extraction from passion fruit peel (Passiflora edulis flavicarpa) using response surface methodology. International Journal of Food Science \& Technology, v. 44, n. 3, p. 476-483, 2009.

KLIEMANN, E. Extração e caracterização da pectina da casca do maracujá amarelo. (Passiflora edulis flavicarpa). Florianópolis, 2006. 75 f. Dissertação (Mestrado em Ciência dos Alimentos)- Departamento de Ciência e Tecnologia de Alimentos- Universidade Federal de Santa Catarina.

MAY, C. D. Industrial pectins: sources, production and applications. Carbohydrate Polymers, v. 12, p.79-99, 1990.

PERES, P. A.; CANTERI-SCHEMIN, M. H. Rendimento da extração de pectina de diferentes partes de maracujá. $\mathbf{6}^{\mathbf{0}}$ Simpósio Latino Americano de Ciência de Alimentos. Campinas, 07-10 nov. 2005. p. 1467.

PÉREZ S.; RODRÍGUEZ-CARVAJAL M. A.; DOCO P. A complex plant cell wall polysaccharide: rhamnogalacturonan II. A structure in quest of a function. Biochimie, v. 85, p. 109-121, 2003.

PINHEIRO E. R. Pectina da casca do maracujá amarelo (Passiflora edulis flavicarpa): otimização da extração com ácido cítrico e caracterização físico-química . Florianópolis, 2007. 79 f. Dissertação (Mestrado em Ciência dos Alimentos)- Departamento de Ciência e Tecnologia de Alimentos- Universidade Federal de Santa Catarina.

PINHEIRO, E. R., SILVA I. M. D. A., GONZAGA L. V., AMANTE E. R., TEÓFILO R. F., FERREIRA M. M. C., AMBONI R. D. M. C. Optimization of extraction of high-ester pectin from passion fruit peel (Passiflora edulis flavicarpa) with citric acid by using response surface methodology. Bioresource Technology, v. 99, n. 13, p. 55615566, fev. 2008.

RENARD C. M. G. C.; GINIES C. Comparison of the cell wall composition for flesh and skin from five different plums. Food Chemistry, v. 114, p. 1042-1049, 2009.

SAKAI, T.; SAKAMOTO, T.; HALlAERT J.; VANDAMME E. Pectin, Pectinase and Protopectinase: production, properties and applications. Advances in applied microbiology, v. 39, p. 213-294, 1993.

SCABIO A.; FERTONANI H. C. R.; CANTERI-SCHEMIN M. H. PETKOWICZ C. L. O.; CARNEIRO E. B. B.; NOGUEIRA A.; WOSIACKI G., 2007. A model for pectin extraction from apple pomace. Brazilian Journal of Food Technology, v. 10, p 259-265, out.-dez. 2007.

SRIAMORNSAK P. Chemistry of Pectin and Its Pharmaceutical Uses: A Review. Silpakorn University International Journal. v. 3, p. 206-228, 2003.

THAKUR B. R.; SINGH R. K. ; HANDA A. K. Chemistry and uses of pectin- a review. Critical Reviews in Food Science and Nutrition, v. 37, n. 01, p. 47-73. 1997. 
VORAGEN A. G. J.; COENEN G.- J.; VERHOEF R. P.; SCHOLS H. A. Pectin, a versatile polysaccharide present in plant cell walls. Structural Chemistry, v. 20, p. 263-275, 2009.

VORAGEN G. J., PILNIK W., ThIBAult J. F., AXELOS M. A. V., RENARD C. M. G. C. In: Food polysaccharides and their applications (SEPHEN A. M., ed.), p 287-339. Marcel Dekker Inc., New York, 1995.

WILLATS W.G.T, KNOX J.P. MIKKELSEN J. D. Pectin: new insights into an old polymer are starting to gel. Trends in Food Science \& Technology, v. 17, p. 97-104, 2006.

YAPO, B. M. Biochemical characteristics and gelling capacity of pectin from yellow passion fruit rind as affected by acid extractant nature. Journal of Agricultural and Food Chemistry, v. 57, p. 1572-1578, jan. 2009 a.

YAPO, B. M. Lemon juice improves the extractability and quality characteristics of pectin from yellow passion fruit by-product as compared with commercial citric acid extractant. Bioresource Technology, v. 100, p. 3147 -3151, 2009b.

YAPO, B. M.; KOFFI K. L. Yellow passion fruit rind- a potencial source of low-methoxyl pectin. Journal of Agricultural and Food Chemistry, v. 54, p. 2738-2744, 2006.

\section{Dados dos autores:}

\section{Nome completo: Maria Helene Giovanetti Canteri}

Filiação institucional: Universidade Tecnológica Federal do Paraná - UTFPR - Ponta Grossa Brasil

Departamento: Coordenação de Alimentos

Função ou cargo ocupado: Docente

Titulação: Doutora

Endereço: Av. Monteiro Lobato, Km. 04-Baraúna-Ponta Grossa/PR, Brasil, CEP: 84016-210

Telefones para contato: (42) 3220-4823 (com.); (42) 3324-6659

e-mail: canteri@utfpr.edu.br

\section{Nome completo: Agnes de Paula Scheer}

Filiação institucional: Universidade Federal do Paraná -UFPR- Curitiba- Brasil

Departamento: Programa de Pós-Graduação em Tecnologia de Alimentos

Função ou cargo ocupado: Docente

Titulação: Doutora

Endereço: Rua Francisco H. dos Santos - S/No. Jardim das Américas Caixa Postal 19011 Curitiba PR, Brasil

81531-980

Telefone para contato: (41) 3361-3232

e-mail: agnesps@ufpr.br

\section{Nome completo: Christian Ginies}

Filiação institucional: Institute National de Recherche Agronomique - INRA - Avignon- France

Departamento: UMR 408-SQPOV

Função ou cargo ocupado: Pesquisador

Endereço: Domaine Saint Paul-Site Agroparc-Avignon cedex 9 -84914

Telefone para contato: (33) 0432722000

e-mail: christian.ginies@inra.fr

\section{Nome completo: Catherine Marie-Genevieve Claire Renard}

Filiação institucional: Institute National de Recherche Agronomique - INRA et Université d'Avignon et Pays de Vaucluse- Avignon- France

Departamento: UMR 408-SQPOV; Ecole Doctoral 
Função ou cargo ocupado: Professor Pesquisador

Titulação: Doutora

Endereço completo: Domaine Saint Paul -Site Agroparc-Avignon cedex 9

84914

Telefone para contato: (33) 0432722000

e-mail: crenard@inra.fr

Nome completo: Gilvan Wosiacki

Filiação institucional: Universidade Estadual de Ponta Grossa

Departamento: Mestrado em Ciência e Tecnologia de Alimentos

Função ou cargo ocupado: Professor Pesquisador

Titulação: Doutor

Endereço: Av. Carlos Cavalcanti, 4748 - Campus Universitário de Uvaranas-CEP 84030-900- Ponta Grossa - Paraná - BRASIL

Telefone para contato: (42) 3220-3093

e-mail: wosiacki@uol.com.br 